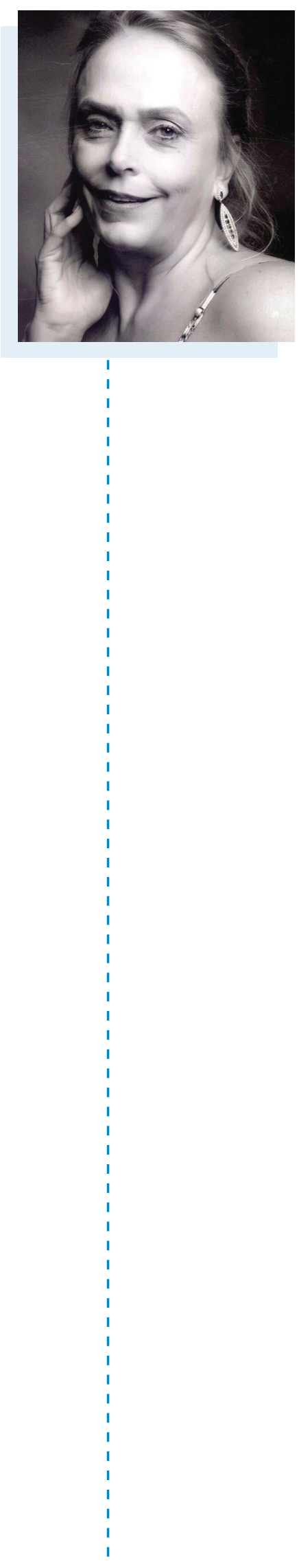

\title{
Nursing: journey and possibilities
}

\author{
Enfermagem: percurso e possibilidades
}

\section{Enfermería: recorrido y posibilidades}

\author{
Maria Angela Boccara de Paula
}

ORCID ID

Paula MAB (D) https://orcid.org/0000-0002-7438-9595
HOW TO CITE

Paula MAB. Enfermagem: percurso e possibilidades. ESTIMA, Braz. J. Enterostomal Ther., 16: e2818. https://doi.org/10.30886/ estima.v16.657

Talking about nursing is talking about many possibilities and opportunities that are present in the daily lives of professionals, because nursing involves knowledge, ethics, responsibility, communication and especially sharing.

Caring is the essence of the nursing professional, who performs its professional practice in different spaces, from the community to the specialized hospital, representing the largest workforce in the health field in Brazil and in the world. It is the professional always present in the 24 hours of the day, acting directly in the care.

It is a profession that transcends the purely technical, which involves the professional who needs to develop different skills, such as "practical competence", through which develops what was planned, seeking to achieve the best results; the "intuitive competence", the one that the professional uses when it perceives beyond its time and space, seeking, whenever possible, new and differentiated alternatives for its work, and for this it is also necessary to have daring; the "intellectual competence", which demands analysis and reflection; and, above all, "emotional competence", a competence of "soul reading", and there must be in its work a great appeal to the affections, which generates harmony and provides empathy ${ }^{1}$.

Caring is your object of work. And caring is complex: it encompasses multiplicity of actions, is to be attentive, coherent and harmonious in order to provide, for those who need this care, safety, since the health-disease process involves uncertainties, fears and, often, temporary changes or definitive.

Thus, the nursing professional experiences daily situations that require the skills to be able to act immediately or just wait and watch, therefore being a great possibility of construction and reconstruction, invention and reinvention, in a rationality that can not be exhausted, but needs 
to be renewed at all times, so that it is possible to develop its work in a way that is consistent with reality and, mainly, in an integrated way with the other members of the health team.

That way, the work of the professionals needs to happen in accordance and harmony with other professionals who work in the health field, aiming to provide quality assistance to those who need it. Thus, interdisciplinary work becomes essential, which is challenging as well, because interdisciplinarity is "attitude", it is action in movement and, according to Fazenda ${ }^{1}$, this, coupled with the dimensions of practice in a real and contextualized situation, which is not always simple or easy, demands attention and desire, because the exchange with other knowledge and the anonymity of the nursing professional requires a special theoretical and ethical stance, which sometimes demands cautious presentations and, often, patience and waiting, since not always their opinions are considered or accepted by other professionals who work in the multidisciplinary team.

In this way, nursing education is also a great challenge, since knowledge expands rapidly, as well as technological development. The nurse professor not only identifies the aspects related to the knowledge of biological man, but knows that this knowledge is not exhausted in the physical and technical dimension and experiences the necessity to conduct the teaching-learning process in nursing for dimensions other than just the concrete or rational, such as, for example, the symbolic and emotional dimension, so that, thus, it is also better able to analyze processes, affectivity, the effect of force and the force of effects, social and institutional dimensions, strategies organizational and, above all, the articulation of these effective knowledge in the daily practice of caring.

And, therefore, nursing research is mandatory and, fortunately, more and more, nurses are dedicated to this field, seeking to investigate and contribute to the construction of theoretical and practical knowledge that may be useful to humanity, also exercising forms interdisciplinary approaches to theorizing and, above all, practicing.

Other fields of work also gain space in the contemporaneity for the nurse and its team. These include auditing, marketing, technical advice, among others.

Multiple knowledge becomes essential for care, contributing to the development of specialized nursing. Thus, nursing has gradually occupied the spaces and it is present in different fields of health care, from direct to indirect care, showing that the nursing professional is "essential and unique" and deserves to be duly recognized for its important social role.

I affirm that when one understands the ambiguity that our body contemplates, we begin to improve the capacity to deal with the other, with the world, thus redeeming the meaning of our work and of life, through lived experience, in an exercise of tolerance and of humility proper to a generosity that inaugurates the nursing of yesterday, today and tomorrow.

\section{REFERENCES}

1. Fazenda ICA. Dicionário em construção: interdisciplinaridade. 2a. ed. São Paulo: Cortez; 2001. 